\title{
MicroRNAs Modulate Oxidative Stress in Hypertension through PARP-1 Regulation
}

\author{
Douglas F. Dluzen, ${ }^{1}$ Yoonseo Kim, ${ }^{1}$ Paul Bastian, ${ }^{2}$ Yongqing Zhang, ${ }^{2}$ Elin Lehrmann, ${ }^{2}$ \\ Kevin G. Becker, ${ }^{2}$ Nicole Noren Hooten, ${ }^{1}$ and Michele K. Evans ${ }^{1}$ \\ ${ }^{1}$ Laboratory of Epidemiology and Population Science, National Institute on Aging, National Institutes of Health, 251 Bayview \\ Boulevard, Baltimore, MD 21224, USA \\ ${ }^{2}$ Laboratory of Genetics and Genomics, National Institute on Aging, National Institutes of Health, 251 Bayview Boulevard, Baltimore, \\ MD 21224, USA
}

Correspondence should be addressed to Nicole Noren Hooten; norenhootenn@mail.nih.gov

Received 24 February 2017; Accepted 22 March 2017; Published 4 June 2017

Academic Editor: Steven McAnulty

Copyright (C) 2017 Douglas F. Dluzen et al. This is an open access article distributed under the Creative Commons Attribution License, which permits unrestricted use, distribution, and reproduction in any medium, provided the original work is properly cited.

Oxidative stress is thought to contribute to aging and age-related diseases, such as cardiovascular and neurodegenerative diseases, and is a risk factor for systemic arterial hypertension. Previously, we reported differential mRNA and microRNA (miRNA) expression between African American (AA) and white women with hypertension. Here, we found that the poly-(ADP-ribose) polymerase 1 (PARP-1), a DNA damage sensor protein involved in DNA repair and other cellular processes, is upregulated in AA women with hypertension. To explore this mechanism, we identified two miRNAs, miR-103a-2-5p and miR-585-5p, that are differentially expressed with hypertension and were predicted to target PARP1. Through overexpression of each miRNAdownregulated PARP-1 mRNA and protein levels and using heterologous luciferase reporter assays, we demonstrate that miR103a-2-5p and miR-585-5p regulate PARP1 through binding within the coding region. Given the important role of PARP-1 in DNA repair, we assessed whether overexpression of miR-103a-2-5p or miR-585-5p affected DNA damage and cell survival. Overexpression of these miRNAs enhanced DNA damage and decreased both cell survival and colony formation. These findings highlight the role for PARP-1 in regulating oxidative DNA damage in hypertension and identify important new miRNA regulators of PARP-1 expression. These insights may provide additional avenues to understand hypertension health disparities.

\section{Introduction}

Systemic arterial hypertension, an age-associated chronic disease, is a predictor of vascular-associated mortality from stroke and ischemic heart disease [1,2]. It affects more than 80 million people $\geq 20$ years old in the United States with increased prevalence over the lifespan [2]. Hypertension disproportionally affects African Americans (AAs) in the United States, particularly in AA women with a prevalence of $>46 \%$, and AAs develop hypertension earlier than whites or any other ethnicity in the United States [2]. Even at similar levels of systolic blood pressure, AAs have a higher risk of stroke compared with whites and death rates attributed to hypertension are higher in both male and female AAs compared with whites or Hispanics [2,3].
The genetic and molecular factors contributing to hypertension disparities are still largely unknown. Perturbations in the renin-angiotensin-aldosterone system (RAAS) and nitric oxide (NO) pathway in immune cells and in the endothelium can contribute to the development of hypertension $[4,5]$, but how these pathways influence disparities in hypertension etiology is not clear. Healthy AA men have elevated production of superoxides in peripheral blood mononuclear cells (PBMCs) compared with white men [6], but investigation of these pathways in healthy or hypertensive AA women has not been investigated. Previously, we identified significant differential gene expression profiles by race and disease status in PBMCs isolated from AA and white women with or without hypertension [7]. We observed that gene expression in 
hypertension-related pathways, in RAAS and other inflammatory pathways, was significantly upregulated in AA hypertensives compared with both normotensive controls and white hypertensives [7].

Gene expression can be regulated by microRNAs (miRNAs), short, single-stranded RNAs which posttranscriptionally regulate protein expression by binding to target mRNAs and inhibiting translation and promoting transcript degradation [8]. miRNAs also can affect transcription by regulating various transcriptional pathways including members of the SWI/SNF chromatin remodeling complex [9]. We examined miRNA expression in AA and white normotensive and hypertensive females and identified differentially expressed miRNAs that regulate hypertensionrelated targets in endothelial cells [7]. MiRNA regulation is essential for proper immune cell [10] and endothelial function $[11,12]$, and altered regulation and expression of these genes can contribute to endothelial dysfunction [13]. miRNA profiles can also serve as biomarkers for cardiovascular diseases (CVDs), such as peripheral arterial disease (PAD) [14].

Differential gene expression in both mRNAs and miRNAs may play a role in hypertension disparities through modulating oxidative stress. Meta-analysis of gene expression datasets of blood samples from patients with cardiovascular disease (CVD) identified differentially expressed genes in oxidative stress and related inflammatory pathways [15]. Endothelial cells from AA women with PAD have increased oxidative stress and reactive oxygen species (ROS) compared to AA men and white women, but the gene expression differences contributing to this were not investigated [16]. Oxidative stress can cause hypertension by promoting ROS production, including the overexpression of nicotinamide adenine nucleotide phosphate (NADPH) oxidases and cyclooxygenases (COXs), which can reduce NO signaling in the endothelium and cause endothelial dysfunction [17-20]. Higher levels of ROS production and oxidative stress can also lead to DNA damage, further promoting inflammatory pathways contributing to hypertension etiology.

Specialized DNA repair pathways are activated by DNA damage leading to signaling cascades that resolve the base or strand damage. Poly-(ADP-ribose) polymerase 1 (PARP-1) is a DNA damage sensor protein that initiates and propagates DNA repair through poly-ADP-ribosylation of key DNA repair proteins $[21,22]$. Many other cellular processes also rely on PARP-1 signaling, and abnormal PARP-1 activity has been attributed to various age-related diseases, including hypertension [23-25]. Consistent with these findings, inhibiting PARP-1 activity in endothelial cells protects against endothelial dysfunction [26, 27] and PARP-1 inhibitors are under consideration as a treatment for pulmonary hypertension [28]. However, differential expression of PARP-1 has not been investigated with respect to health disparities in essential hypertension. Furthermore, racial differences in oxidative stress gene pathways in hypertension have not been fully explored.

We report here that AA women with hypertension exhibit elevated expression of genes in oxidative stress and DNA damage response pathways. Through bioinformatic and pathway analysis, we have identified two novel miRNA regulators of PARP-1 protein expression, miR-103a-2-5p and miR-585-5p, that influence the DNA damage response and cell survival in primary endothelial cells. Identifying the mechanisms governing differential expression of oxidative stress and inflammatory pathways could ultimately provide novel avenues to explore for therapeutic intervention.

\section{Materials and Methods}

2.1. Study Participants. A subcohort of age-matched, African American (AA) and white females who were either normotensive (NT) or hypertensive (HT) were chosen from the Healthy Aging in Neighborhoods of Diversity across the Life Span (HANDLS) study of the National Institute on Aging Intramural Research Program (NIA IRP), National Institutes of Health (NIH). More information about the HANDLS cohort can be found in [29]. The Institutional Review Board of the National Institute of Environmental Health Sciences, NIH, approved this study, and all participants signed written informed consent documents. The subcohort consists of WNT, WHT, AANT, and AAHT ( $n=20$ /group for validation) females, and more extensive demographic and clinical information about this cohort have been previously described [7].

2.2. Cell Culture, Transfection, and RNA Isolation. Primary human aortic endothelial cells (HAEC) were grown in EMB-2 supplemented with the EGM-2 SingleQuot Kit (Lonza; Walkersville, MD). HUVECs were grown in EBM supplemented with the EGM SingleQuot Kit (Lonza). HeLa cells were grown in Dulbecco's modified Eagle's medium (DMEM, Invitrogen) and supplemented with $10 \%$ fetal bovine serum (FBS). Cells were transfected with pre-miR miRNA precursors for hsa-miR-103a-2-5p, hsa-miR-585$5 \mathrm{p}$, or scrambled (Scr) negative control (Life Technologies) using Lipofectamine 2000 (Life Technologies). Total RNA from HUVECs and HAECs was isolated using TRIzol (Life Technologies). RNA quality was measured by a Nanodrop 2000.

2.3. Microarray Analysis and Target Prediction. mRNA expression in HAECs was analyzed by microarray using the Illumina Beadchip HT-12v4 (Illumina, San Diego, CA). RNA was prepared and labeled per the manufacturer's protocol. Raw signal data were subjected to Z-score normalization per [30] to ensure compatibility and normalization. Individual genes with $Z$-ratios $<-1.5$-fold, $p$ value $<0.05$, and average intensity $>0$ were considered significant. The DIANA-microT prediction algorithm [31] and Ingenuity Pathway Analysis (IPA; Ingenuity Systems, Redwood City, CA) were used to identify mRNA targets for miR-103a-2$5 \mathrm{p}$ and miR-585-5p as well as to visualize functional, hierarchical relationships between target predictions (as seen in Figure 1). IPA network analysis was performed as previously described [7], using both the default setting analysis and custom prediction modeling features. All microarray data can be found on Gene Expression Omnibus GSE95431.

2.4. RT-qPCR Analysis. mRNA from HAECs and HUVECs was transcribed into cDNA using random hexamers and 


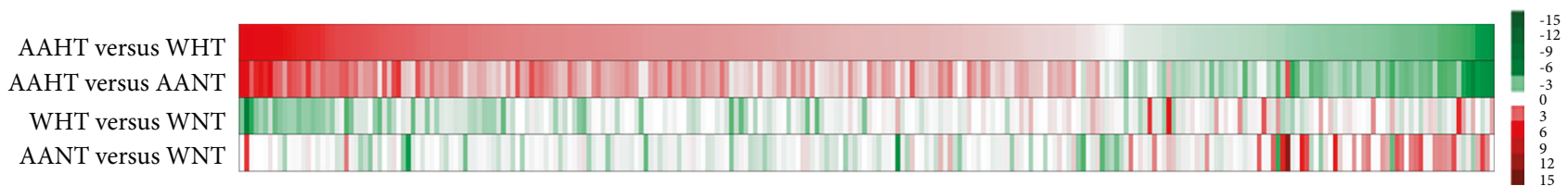

(a)

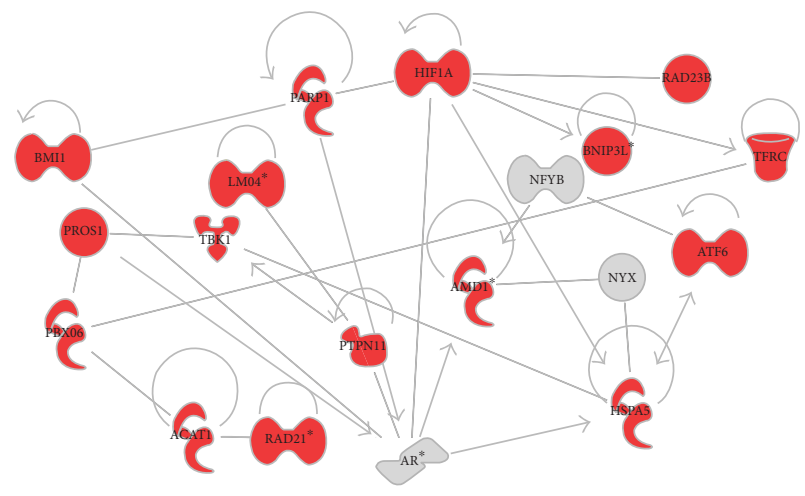

AAHT versus WHT

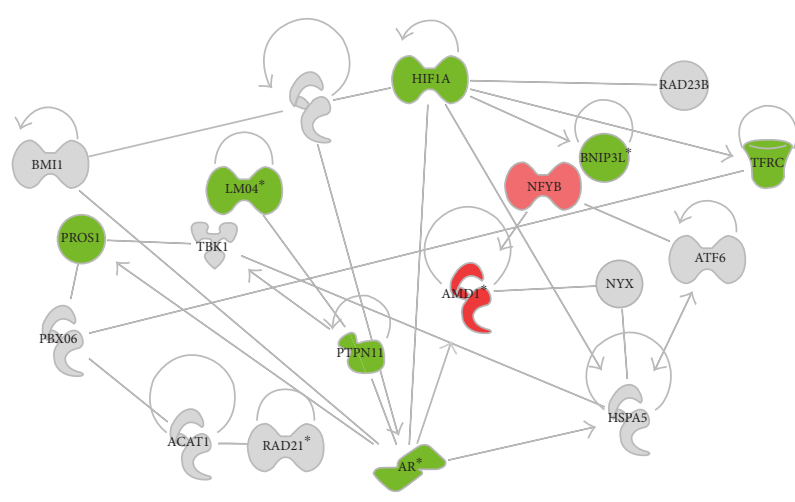

WHT versus WNT

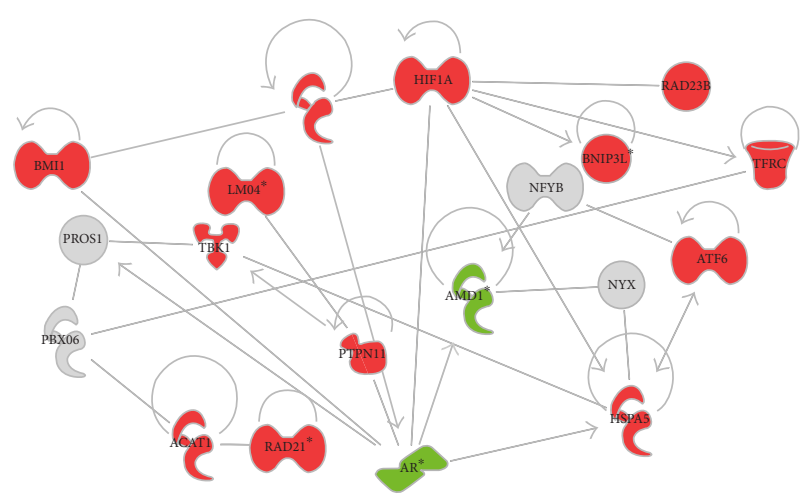

AAHT versus AANT

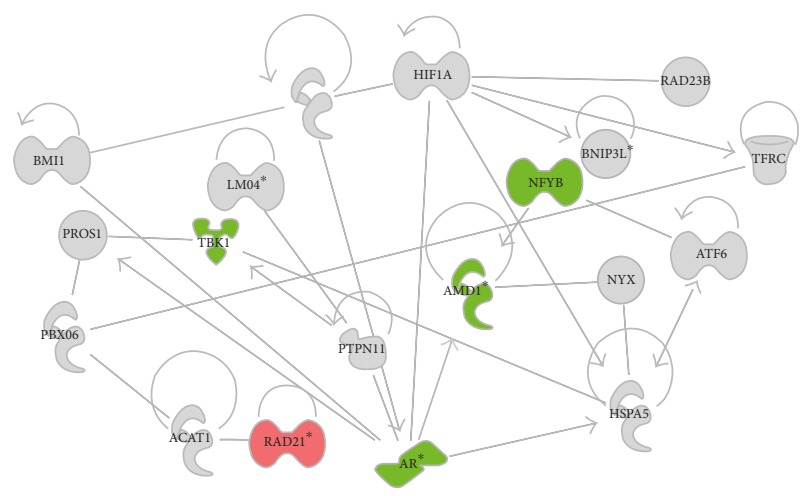

AANT versus WNT

(b)

FIGURE 1: Pathway analysis of gene expression in hypertensive women. (a) Heat map of significantly changed genes identified from top canonical and physiological pathways and functions in HAECs after overexpression of miR-103a-20-5p and miR-585-5p miRNA mimics. Red (up) and green (down) indicate relative Z-ratios of significantly and-differentially expressed mRNAs in PBMCs from our hypertension cohort and reflect changes in AAHT compared with WHT or AANT, WHT with WNT, and AANT with WNT. (b) IPA-curated, hierarchal clustering of functional relationships between individual genes predicted to be targets of either miR-103a2-5 or miR-585-5p. Red (up) and green (down) indicate relative fold change of significantly and differentially expressed mRNAs in PBMCs from our hypertension cohort in each comparison. AAHT: AA hypertensives; AANT: AA normotensives; WHT: white hypertensives; WNT: white normotensives.

Script II reverse transcriptase (Invitrogen), and miRNA was transcribed into cDNA using the QuantiMiR RT Kit (Systems Biosciences, Mountain View, CA). Transcript levels were assessed by RT-qPCR using $2 \mathrm{x}$ SYBR green master mix (Applied Biosystems) on an Applied Biosystems model 7500 real-time PCR machine. PARP1 levels were normalized to the average of $A C T B$ and $G A P D H$, and $\mathrm{miR}$ $103 a-2-5 p$ and miR-585-5p were normalized to U6. All gene expression levels were calculated using the $2^{-\Delta \Delta C t}$ method [32]. The following primers were used (forward and reverse, respectively, for each mRNA): GGACTTCGAGCAAGAGATGG and AGCACTGTGTTGGCGTACAG for
ACTB, GCTCCTCCTGTTCGACAGTCA and ACCTTCC CCATGGTGTCTGA for GAPDH, and CGAGATCATC AGGAAGTATGTTAAGAA and GCTGGCATTCGCCTT CAC for PARP1. The following forward primers were used for each miRNA and used with the U6 forward primer and universal reverse primer provided with the QuantiMiR RT Kit: AGCTTCTTTACAGTGCTGCCTTG for miR103a-2-5p and CTAGCACACAGATACGCCCAGA for miR-585-5p.

2.5. Western Blot Analysis. HAECs and HUVECs were washed twice with cold PBS and lysed in 2x Laemmli sample 
buffer. Lysates were loaded onto a 10\% acrylamide gel, and protein levels were assessed by immunoblotting with antiPARP-1 (Cell Signaling) and anti-GAPDH (Santa Cruz, Dallas, TX) or anti-Actin (Santa Cruz) antibodies.

2.6. Luciferase Reporter Assays. The cDNA fragments corresponding to the partial PARP1 mRNAs were amplified by PCR using specific primers. After XhoI and NotI digestion, the PCR product was cloned downstream of the Renilla open reading frame of the psiCHECK2 reporter plasmid. HeLa cells were transfected with $500 \mathrm{ng}$ of the indicated luciferase reporter constructs and transfected again $24 \mathrm{hrs}$ later with the miRNA mimics or Scr control. Twenty-four hours later, RL and FL activities were measured using the DualLuciferase ${ }^{\circledR}$ Reporter Assay System (Promega) per the manufacturer's instructions. The following primers were used (forward and reverse, respectively): GCATCTCGAGATGGC GGAGTCTTCGGATAAGC and GCATGCGGCCGCTGT GGAGGGC GGAGGCGTG for $P A R P 1(C R-a)$ and GCATC TCGAGGGTACGGTGATCGGTAGCAA and GCATGCG GCCGCCTTGTAACGCTGGCATTCGC for PARP1(CR-b).

2.7. Single Cell Gel Electrophoresis (Comet) Assays. Fortyeight hours after transfection with pre-miRNA precursors for hsa-miR-103a, hsa-miR-585-5p, or Scr control, HAECs were untreated or treated with $100 \mu \mathrm{M} \mathrm{H}_{2} \mathrm{O}_{2}$ for $30 \mathrm{~min}$ in serum-free EMB-2. This concentration of $\mathrm{H}_{2} \mathrm{O}_{2}$ induces various base lesions and DNA breaks. Single-cell alkaline comet assays were performed essentially as described [33, 34]. Comets were imaging on an Eclipse E-400 fluorescence microscope (Nikon, Japan) attached to a Pulnix video camera (Kinetic Imaging, LTD, Liverpool, UK) and were quantified using Komet 5.5 software (Kinetic Imaging LTD). Olive tail moment was used as a measure of DNA damage level $[35,36]$.

2.8. Immunofluorescence. Forty-eight hours after transfection, HAECs were untreated or treated with $10 \mu \mathrm{M}$ menadione for $30 \mathrm{~min}$ in serum-free EMB-2. Cells were stained for 8-oxo-7,8-dihydroguanine (8-oxoG) and 4',6-diamidino-2phenylindole (DAPI) as previously described [37] using an anti-8-oxoG monoclonal antibody from Millipore and Alexa-568 conjugated secondary antibodies from Invitrogen. Images were taken on a Zeiss Observer D1 microscope with an AxioCam1Cc1 camera at a set exposure, and fluorescence intensity was measured for each 8-oxoG stained nuclei using AxioVision Rel 4.7 software.

2.9. Colony Formation and Cell Survival Assays. For the colony formation assays, HAECs were transfected with premiRNA precursors miR-103a-2-5p or miR-585-5p cells or Scr control, and $24 \mathrm{hrs}$ later, cells (3000/well) were plated in 6-well plates in triplicate and allowed to attach for $24 \mathrm{hrs}$. HAECs were treated with or without $50 \mu \mathrm{M} \mathrm{H}_{2} \mathrm{O}_{2}$ for 7 days. The media with or without $50 \mu \mathrm{M} \mathrm{H}_{2} \mathrm{O}_{2}$ was changed once during the time of the assay. Colonies were stained with $0.5 \%$ Crystal violet in 50\% methanol. Plates were washed with PBS and were imaged. Only colonies with $>100$ cells were counted.
Scr control, miR-103a-2-5p, or miR-585-5p cells (5000/well) were plated in a 96-well plate. The following day, cells were untreated or treated for $24 \mathrm{~h}$ with $100 \mu \mathrm{M} \mathrm{H}_{2} \mathrm{O}_{2}$. Cell survival was measured using a MTT assay (Sigma).

2.10. Statistical Analysis. Student's $t$-test was used when comparing two groups, unless otherwise noted. A $p$ value of $<0.05$ was considered statistically significant.

\section{Results}

3.1. Identification and Analysis of Hypertension-Related MicroRNAs and Genes. We previously reported that there is significant, differential mRNA and miRNA expression by race and/or hypertension status in PBMCs isolated from AA and white women. Nine miRNAs were differentially expressed in our cohort. We bioinformatically identified and confirmed novel hypertension-related mRNA targets for five of these miRNAs in primary human endothelial cells [7]. In the present study, we sought to identify and confirm novel hypertension-related mRNA targets for two more miRNAs differentially expressed in our previous cohort, miR-103a-2-5p and miR-585-5p, which until then had never been associated with essential hypertension.

We have identified potential mRNA targets for miR103a-2-5p and miR-585-5p using the DIANA-microT prediction algorithm [31] and Ingenuity Pathway Analysis (IPA). miR-103a-2-5p and miR-585-5p are predicted to target 4031 and 255 mRNAs, respectively (Supplemental Dataset 1 available online at https://doi.org/10.1155/2017/ 3984280). To confirm these predictions in vitro, we individually overexpressed miR-103a-2-5p, miR-585-5p, and scrambled ( $\mathrm{Scr}$ ) control miRNA mimics in primary human aortic endothelial cells (HAECs). Total RNA was isolated to assess global gene expression levels via microarray. A total of 1178 and 1112 unique mRNAs were significantly downregulated $>1.5$-fold in the presence of miR-103a-2-5p and miR-585-5p mimics, respectively (Supplemental Dataset 1). For miR-103a-2-5p, twenty-nine mRNAs were both repressed in HAECs and differentially expressed in hypertension-related pathways in PMBCs in our previous cohort; however, there were no targets identified for miR585-5p using this approach (Supplemental Data Set 1).

We next used IPA to identify the top canonical and physiological pathways and functions in HAECs that exhibited significant gene expression differences in the presence of each miRNA mimic (Table 1; Columns II and III). Additionally, we identified which genes from each pathway that were significantly repressed by each miRNA mimic and differentially expressed in PBMCs in our hypertension cohort (Table 1). Of the top five, significantly altered canonical pathways, miR-103a-2-5p was predicted to regulate HSPA 5 and RAD21, while there were no targets identified for miR-585-5p. Of the top significantly changed molecular, cellular, and physiological pathways in HAECs, miR-103a2-5p and miR-585-5p were predicted to target mRNAs related to DNA replication, recombination, and repair and cellular growth and proliferation. miR-103a-2-5p and miR- 
TABLE 1: Summary of HAEC pathway analysis.

\begin{tabular}{|c|c|c|c|c|c|c|}
\hline MicroRNA & $\begin{array}{c}\text { II. Top } \\
\text { canonical } \\
\text { pathways in } \\
\text { HAECs }\end{array}$ & $P$ value & $\begin{array}{c}\text { DIANA or IPA-predicted } \\
\text { pathway targets } \\
\text { repressed } \geq 1.5 \text {-fold in } \\
\text { HAECs \& differentially } \\
\text { expressed in PBMCs }\end{array}$ & $\begin{array}{l}\text { III. Top molecular } \\
\text { and cellular functions } \\
\text { and physiological } \\
\text { systems in HAECs }\end{array}$ & $P$ value & $\begin{array}{l}\text { DIANA or IPA-predicted } \\
\text { pathway targets } \\
\text { repressed } \geq 1.5 \text {-fold in } \\
\text { HAECs \& differentially } \\
\text { expressed in PBMCs }\end{array}$ \\
\hline \multirow[t]{6}{*}{$\begin{array}{l}\operatorname{miR}-103 a- \\
2-5 p\end{array}$} & EIF2 signaling & $1.4 \times 10^{-10}$ & N/A & $\begin{array}{l}\text { Cell death and } \\
\text { survival }\end{array}$ & $\begin{array}{l}1.6 \times 10^{-3} \\
4.3 \times 10^{-22}\end{array}$ & $\begin{array}{c}\text { ATF6, BMI1, BNIP3L, } \\
\text { HIF1A, HSPA5, LMO4, } \\
\text { PARP1, PTPN11, RAD21, } \\
\text { RAD23B, TFRC }\end{array}$ \\
\hline & $\begin{array}{c}\text { Protein } \\
\text { ubiquitination }\end{array}$ & $3.2 \times 10^{-8}$ & HSPA5 & Cell cycle & $\begin{array}{l}1.8 \times 10^{-3} \\
1.1 \times 10^{-20}\end{array}$ & BMI1, HIF1A, RAD21, TFRC \\
\hline & $\begin{array}{c}\text { Interferon } \\
\text { signaling }\end{array}$ & $4.5 \times 10^{-8}$ & $\mathrm{~N} / \mathrm{A}$ & $\begin{array}{c}\text { Cellular assembly and } \\
\text { organization }\end{array}$ & $\begin{array}{l}1.5 \times 10^{-3} \\
1.1 \times 10^{-20}\end{array}$ & PARP1, RAD21 \\
\hline & $\begin{array}{l}\text { Mitotic roles } \\
\text { of polo-like } \\
\text { kinase }\end{array}$ & $7.9 \times 10^{-8}$ & RAD21 & $\begin{array}{l}\text { DNA replication, } \\
\text { recombination, and } \\
\text { repair }\end{array}$ & $\begin{array}{l}1.6 \times 10^{-3} \\
1.1 \times 10^{-20}\end{array}$ & $\begin{array}{c}\text { BMI1, PARP1, RAD23B, } \\
\text { PARP1 }\end{array}$ \\
\hline & $\begin{array}{l}\text { Cell cycle } \\
\text { control of } \\
\text { chromosomal } \\
\text { replication }\end{array}$ & $1.6 \times 10^{-7}$ & N/A & $\begin{array}{l}\text { Cellular growth and } \\
\text { proliferation }\end{array}$ & $\begin{array}{l}1.8 \times 10^{-3} \\
9.1 \times 10^{-19}\end{array}$ & $\begin{array}{c}\text { ACAT1, AMD1, BMI1, } \\
\text { HIF1A, HSPA5, PARP1, } \\
\text { PROS1, RAD21, TFRC, } \\
\text { TPN11 }\end{array}$ \\
\hline & & & & $\begin{array}{l}\text { Cardiovascular } \\
\text { system development } \\
\text { and function }\end{array}$ & $\begin{array}{l}1.3 \times 10^{-3}- \\
4.1 \times 10^{-7}\end{array}$ & HSPA5, PROS1 \\
\hline \multirow[t]{6}{*}{$\begin{array}{l}\operatorname{miR}-585- \\
5 \mathrm{p}\end{array}$} & EIF2 signaling & $2.3 \times 10^{-15}$ & N/A & $\begin{array}{l}\text { Cell death and } \\
\text { survival }\end{array}$ & $\begin{array}{l}6.9 \times 10^{-4} \\
2.1 \times 10^{-22}\end{array}$ & PARP1 \\
\hline & $\begin{array}{l}\text { Mitotic roles } \\
\text { of polo-like } \\
\text { kinase }\end{array}$ & $6.6 \times 10^{-9}$ & N/A & Cell cycle & $\begin{array}{l}7.7 \times 10^{-4} \\
5.2 \times 10^{-21}\end{array}$ & $\mathrm{~N} / \mathrm{A}$ \\
\hline & $\begin{array}{l}\text { Cell cycle } \\
\text { control of } \\
\text { chromosomal } \\
\text { replication }\end{array}$ & $9.2 \times 10^{-9}$ & N/A & $\begin{array}{c}\text { Cellular assembly and } \\
\text { organization }\end{array}$ & $\begin{array}{l}7.6 \times 10^{-4} \\
1.1 \times 10^{-19}\end{array}$ & PARP1 \\
\hline & $\begin{array}{l}\text { Regulation of } \\
\text { eIF4 and } \\
\text { p70S6K } \\
\text { signaling }\end{array}$ & $3.3 \times 10^{-8}$ & N/A & $\begin{array}{l}\text { DNA replication, } \\
\text { recombination, and } \\
\text { repair }\end{array}$ & $\begin{array}{l}5.4 \times 10^{-4}- \\
1.1 \times 10^{-19}\end{array}$ & PARP1 \\
\hline & $\begin{array}{l}\text { mTOR } \\
\text { signaling }\end{array}$ & $7.5 \times 10^{-8}$ & N/A & $\begin{array}{l}\text { Cellular growth and } \\
\text { proliferation }\end{array}$ & $\begin{array}{l}5.3 \times 10^{-4} \\
9.1 \times 10^{-17}\end{array}$ & N/A \\
\hline & & & & $\begin{array}{l}\text { Cardiovascular } \\
\text { system development } \\
\text { and function }\end{array}$ & $\begin{array}{l}6.8 \times 10^{-4} \\
1.2 \times 10^{-10}\end{array}$ & PARP1 \\
\hline
\end{tabular}

585-5p were both predicted to target $P A R P 1$, and miR-103a$2-5 p$ was predicted to regulate the expression of fourteen additional mRNAs related to these pathways (Table 1).

We next sought to identify any disease or racial differences in gene expression of these pathways in our hypertension cohort. We generated a heat map of the Z-ratios of all genes in PBMCs from our hypertension cohort that are found in the pathways significantly affected by miR-103a-2$5 p$ and miR-585-5p overexpression in HAECs (Figure 1(a)). We observed that AA women with hypertension (AAHT) had significantly elevated global gene expression in these pathways with respect to both AA normotensive controls (AANT) and white women with hypertension (WHT). Gene expression levels were decreased in WHT compared with white normotensive controls (WNT), and in general, few genes were significantly different when comparing AANT with WNT. Of those that were significantly different, they were most often upregulated in AANT (Figure 1(a)). These data suggest that there are unique genes and gene expression profiles differentially expressed and associated with hypertension status and race that are potentially regulated by miR-103a-2-5p and miR-585-5p.

We next used IPA to build a curated, hierarchal cluster of functional relationships between individual genes predicted to be targets of each miRNA, significantly repressed in HAECs and differentially expressed in our hypertension cohort (Figure 1(b)). We observed that PARP1 and related genes are significantly overexpressed in AAHT compared with WHT or AANT, reflecting the global profiles discussed above. The same genes are predominately repressed in WHT 


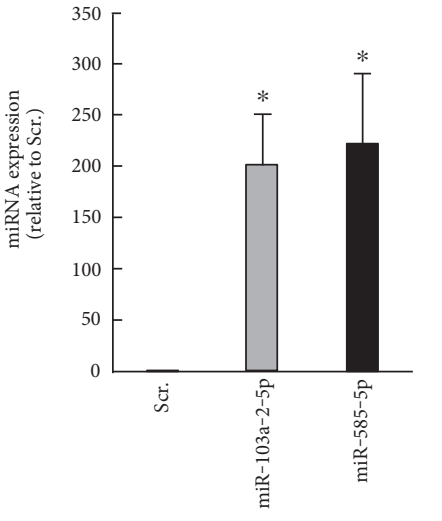

(a)

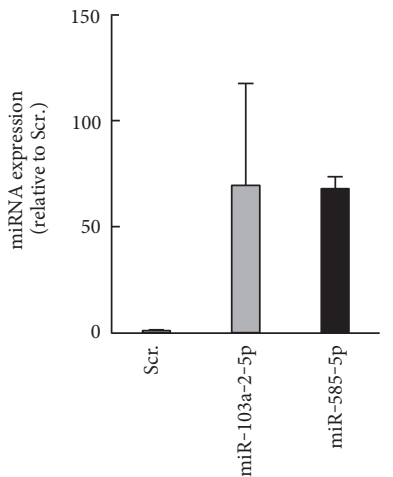

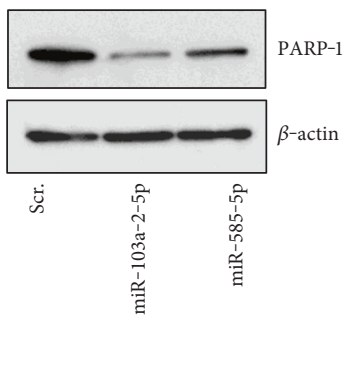

(b)
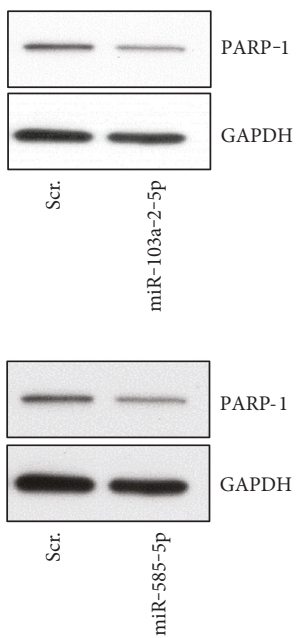

(d)
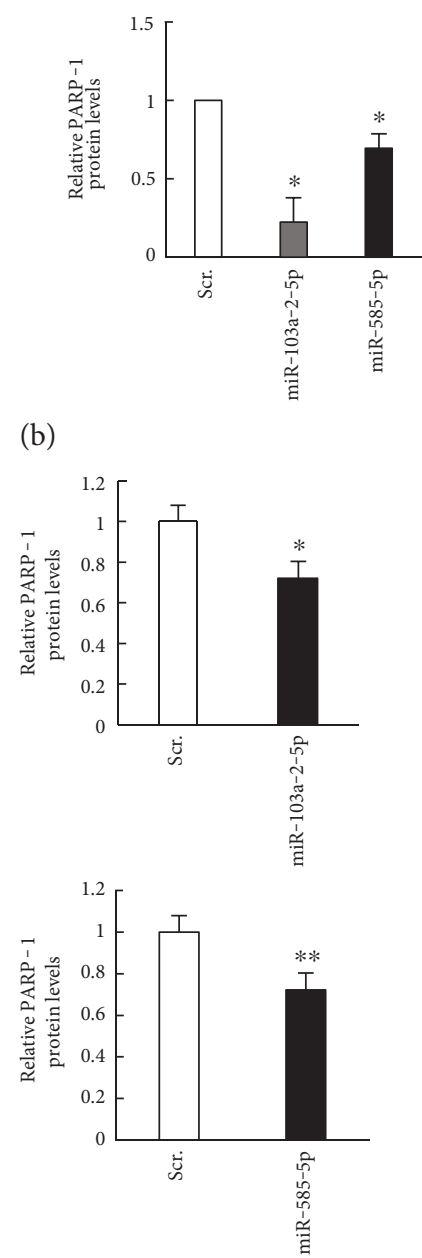

FIgURE 2: miR-103-2-5p and miR-585-5p decrease PARP-1 expression. HAECs $(a, b)$ or HUVECs $(c$, d) were transfected with precursor mimics for miR-103-2-5p, miR-585-5p, or scrambled (Scr) control. After $48 \mathrm{hrs,} \mathrm{cells} \mathrm{were} \mathrm{lysed} \mathrm{for} \mathrm{RNA} \mathrm{and} \mathrm{protein} \mathrm{analysis.} \mathrm{(a,} \mathrm{c)}$ miRNA and PARP1 mRNA levels were quantified by RT-qPCR analysis. (b, d) Lysates were analyzed by SDS-PAGE and immunoblotted with anti-PARP-1, anti-GAPDH, and anti- $\beta$-actin antibodies. Histograms represent the mean + SEM and from three independent experiments ${ }^{*} P<0.05$ and $P<0.01$ by Student's $t$-test.

compared to WNT, and most genes, except for RAD21, $T B K 1, N F Y B, A M D 1$, and $A R$, are not differentially expressed when comparing AA and white normotensive controls (Figure 1(b)). These data suggest that genes involved with DNA repair, endothelial cell growth, and cardiovascular function exhibit differential expression in hypertension by race and may contribute to differences observed in hypertension health disparities in women [7].

3.2. $m i R-103 a-2-5 p$ and miR-585-5p Regulate PARP1 Expression. Given that miR-103a-2-5p and miR-585-5p are both predicted to target PARP1, and PARP-1 has previously been implicated in hypertension pathology, we examined whether miR-103a-2-5p and miR-585-5p regulate PARP-1 expression. To test this, we overexpressed these miRNAs by transfecting precursors into human aortic endothelial cells (HAEC) and human umbilical vein endothelial cells (HUVEC). miR-103a-2-5p and miR-585-5p overexpression decreased PARP-1 mRNA and protein abundance (Figure 2), indicating that PARP-1 levels can be modulated by these miRNAs.

To further confirm that miR-103a-2-5p and miR-585-5p regulate PARP-1 expression, we used heterologous luciferase reporter plasmids (Figure 3) that express Renilla luciferase (RL) from constructs lacking or containing the PARP1 CR (psiCHECK2 or psiCHECK2-PARP1-CR- $a$ and CR- $b$ ). These plasmids also contain Firefly luciferase (FL), which served as an internal transfection control. The ratio of RL/FL activity from each transfected reporter plasmid indicated that miR$103 a-2-5 p$ significantly decreased the levels of psiCHECK2- 


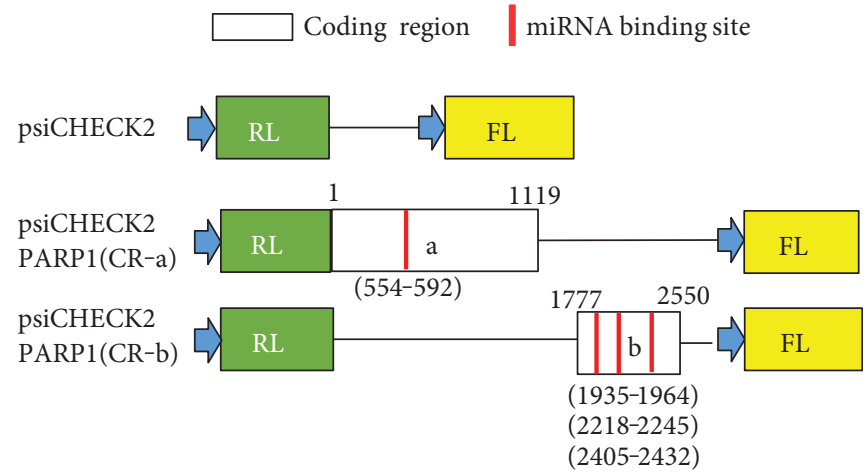

(a)

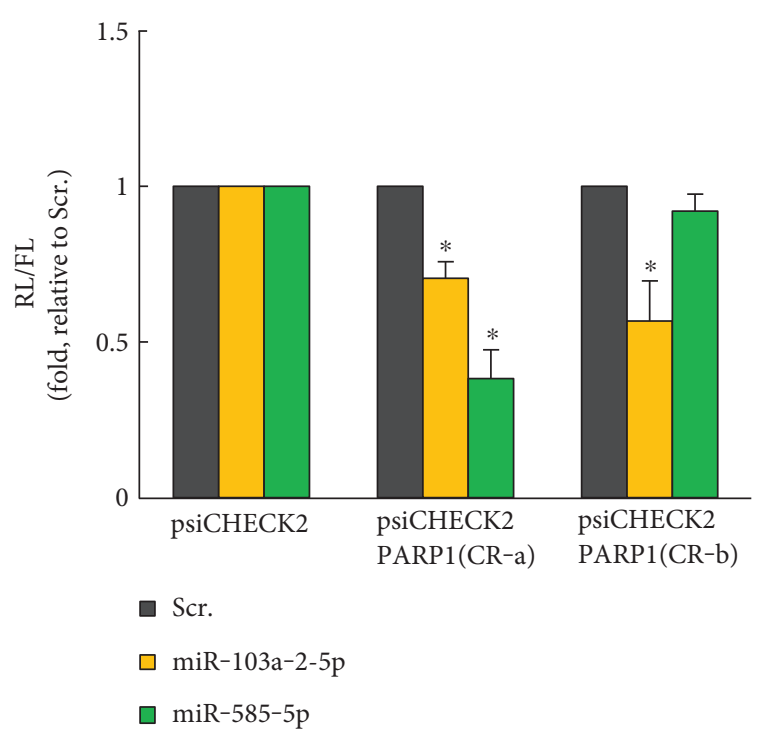

(b)

Figure 3: miR-103-2-5p and miR-585-5p target PARP-1. (a) Schematic of PARP1 coding region (CR) dual-luciferase reporter constructs. psiCHECK2 control plasmid expresses both the Renilla luciferase (RL) and Firefly luciferase (FL). Constructs of the PARP1(CR) span the indicated predicted miRNA binding sites (red color bars). (b) Cells were transfected with the dual-luciferase constructs and the indicated miRNAs or scrambled control (Scr). The ratio of RL/FL activity is shown. The histogram represents the mean + SEM from three independent experiments. ${ }^{*} P<0.05$ by Student's $t$-test compared to Scr.

PARP1 CR- $a$ and $C R-b$. miR-585-5p reduced the levels of psiCHECK2-PARP1 $C R-a$, while it did not affect the activity of the psiCHECK2- PARP1 CR-b reporter (Figure 3(b)). These data suggest that miR-103a-2-5p and miR-585-5p regulate PARP-1 through areas in the PARP1 coding region. Although uncommon, miRNA regulation of mRNA transcripts in the coding region can inhibit translation [38]. Bioinformatic analyses using DIANA-microT [31] predicted that miR-103a-2-5p has four binding sites within the PARP1 coding region (CR) but did not identify a binding site for miR-585-5p. We observed that miR-585-5p does functionally regulate the PARP1 coding region and this may be through a noncanonical miRNA binding site [39, 40]. We identified potential noncanonical sites for miR-585-5p in this area of the PARP1 coding region. Target prediction analysis did not identify binding sites for either miRNA in the $3^{\prime}$ UTR of PARP1.

3.3. miR-103a-2-5p and miR-585-5p Enhance DNA Damage. Given the important role that PARP-1 plays as a DNA damage sensor and in DNA repair, we assessed whether overexpression of miR-103a-2-5p and miR-585-5p enhanced DNA damage. To initially test this idea, we examined whether miR-103a-2-5p and miR-585-5p affected DNA damage levels using the single-cell gel electrophoresis (comet) assay under alkaline conditions, which measures alkaline-sensitive sites including DNA breaks, alkaline labile sites, and transient repair sites. In the absence of DNA damage, there was very little difference in the amount of endogenous DNA damage between scrambled control and miR-585-5p and miR-103a-2-5p transfected cells, although there was a slight enhancement of DNA damage in miR- 103a-2-5p transfected cells, but this did not reach significance (Figures 4(a) and 4(b)). However, after treatment with the DNA-damaging agent $\mathrm{H}_{2} \mathrm{O}_{2}$, there was a significant increase in the amount of DNA damage in both miR-585$5 p$ and miR-103a-2-5p transfected cells compared with control transfected cells (Figures 4(a) and 4(b)).

We also addressed whether miRNA overexpression affected levels of the DNA base lesion, 8-oxoG, which can be detected in HAECs by immunostaining. DNA base lesions, including 8 -oxoG, are repaired by proteins in the base excision repair pathway, including PARP-1. Endogenous 8-oxoG levels were higher in cells transfected with miR-103a-5-5p or miR-585-5p (Figure 4(c)). Treatment with the DNA-damaging agent menadione induces DNA base lesions. miR-103a-2-5p or miR-585-5p transfection increased 8-oxoG levels over control transfected cells after treatment with menadione. In summary, these data indicate that miR-103a-2-5p and miR-585-5p enhance DNA damage.

3.4. miR-103a-2-5p and miR-585-5p Decrease Cell Survival and Colony Formation. Given that higher levels of DNA damage can sometimes decrease cell survival, we investigated whether miR-103a-2-5p and miR-585-5p affected cell survival with both short or prolonged exposures to DNAdamaging agents. miR-103a-2-5p and miR-585-5p transfected cells were exposed to a prolonged low dose of $\mathrm{H}_{2} \mathrm{O}_{2}$ to mimic physiological treatment conditions. Overexpression of these miRNAs significantly decreased colony formation with or without $\mathrm{H}_{2} \mathrm{O}_{2}$ treatment (Figures 5(a) and 5(b)). We also treated cells with a higher dose of $\mathrm{H}_{2} \mathrm{O}_{2}$ for a shorter time to address the effects on cell survival. 

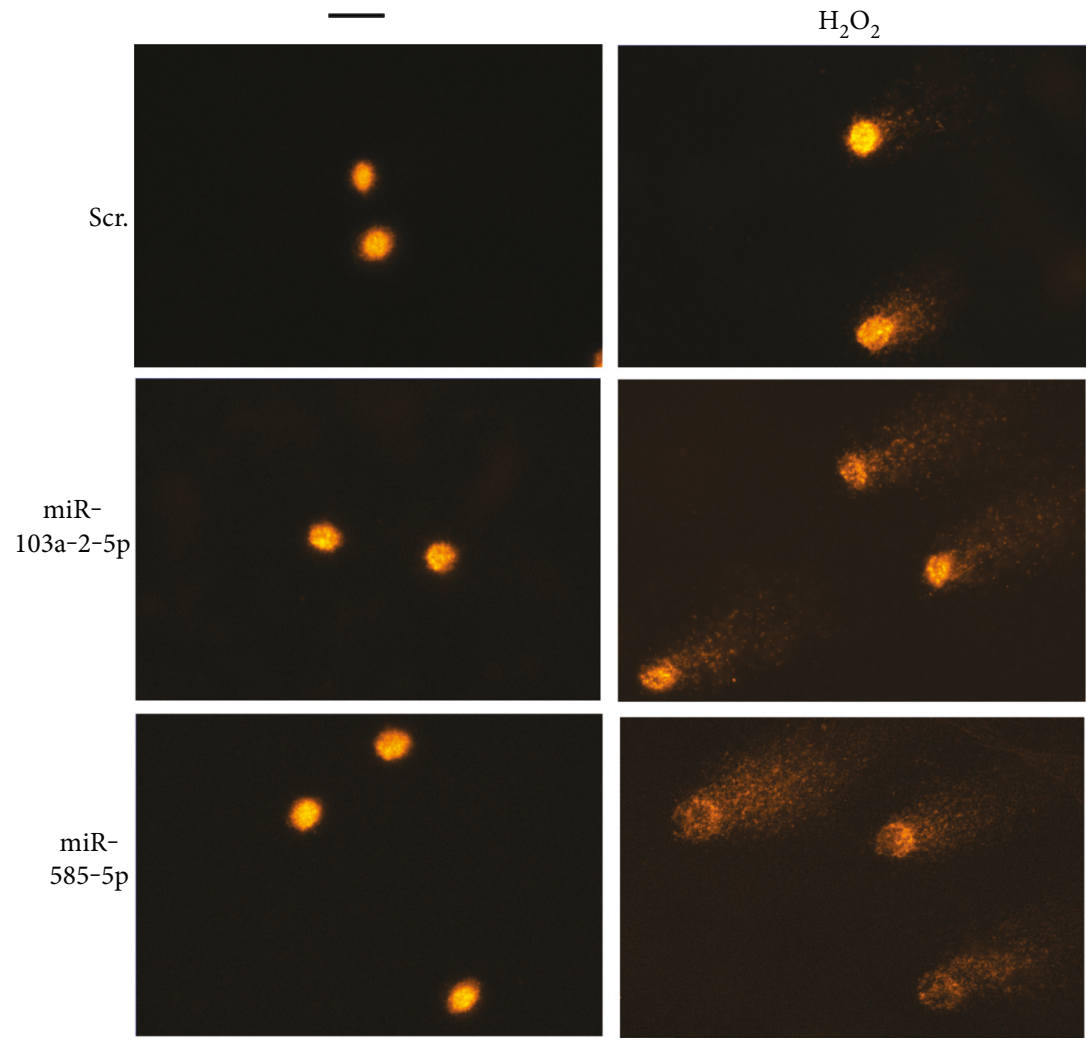

(a)

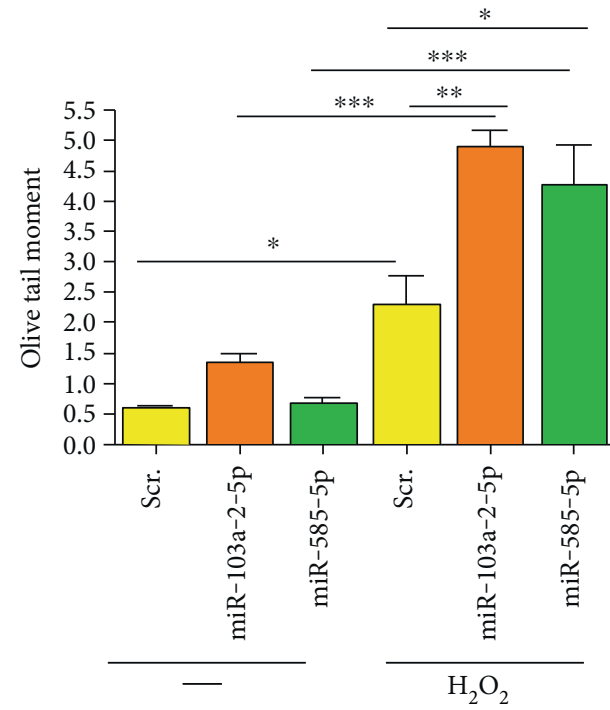

(b)

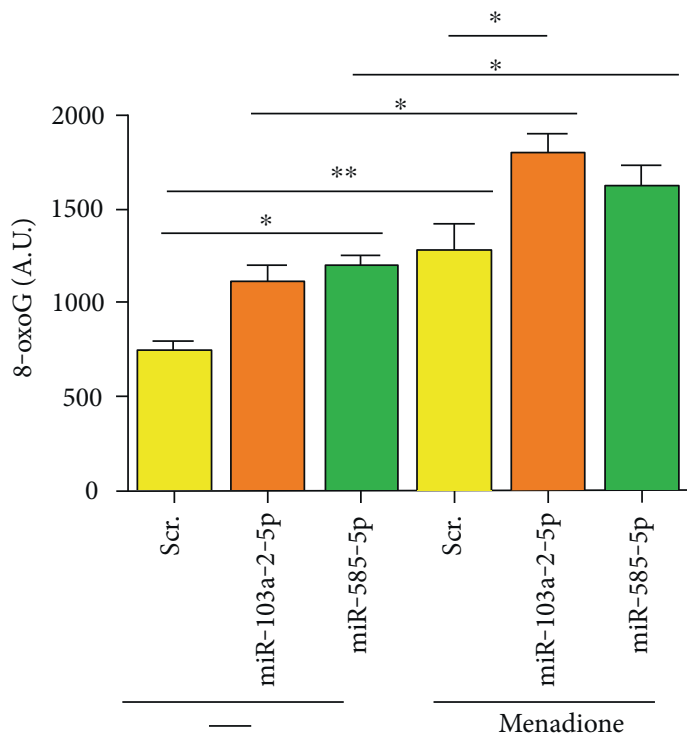

(c)

FIGURE 4: miR-103a-2-5p and miR-585-5p enhance DNA damage. HAECs were transfected with precursor mimics of miR-103a-2-5p, miR585-5p, or scrambled control (Scr). Forty-eight hrs after transfection, cells were untreated (-) or treated with $100 \mu \mathrm{M} \mathrm{H}_{2} \mathrm{O}_{2}$ for 30 min and comet assays were performed under alkaline conditions. Representative comets are shown in (a), and olive tail moment was used as a measure of DNA damage (b). (c) Forty-eight hours after transfection with the indicated miRNAs, HAECs were untreated (-) or treated with $10 \mu \mathrm{M}$ menadione (men) for $30 \mathrm{~min}$. Cells were stained with anti-8oxoG antibodies, and fluorescent intensity was calculated as described in the Materials and Methods. The histograms represent the mean of 3 independent experiments $+\mathrm{SEM}$. ${ }^{*} P<0.05,{ }^{* *} P<0.01$, ${ }^{* * *} P<0.001$ for the indicated comparisons using one-way ANOVA and Tukey's post hoc test.

Similar to the colony formation assays, overexpression of miR-103a-2-5p and miR-585-5p significantly reduced cell survival both in the presence and absence of DNA damage
(Figure 5(c)). Collectively, these data suggest that miR$103 a-2-5 p$ and miR-585-5p reduce endothelial cell survival potentially through modulation of PARP-1 expression. 


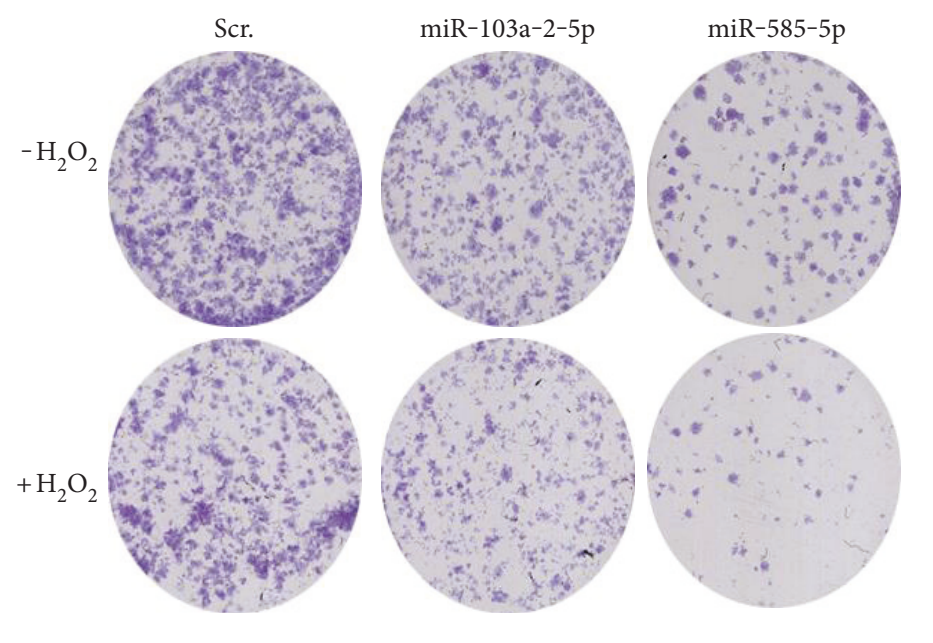

(a)

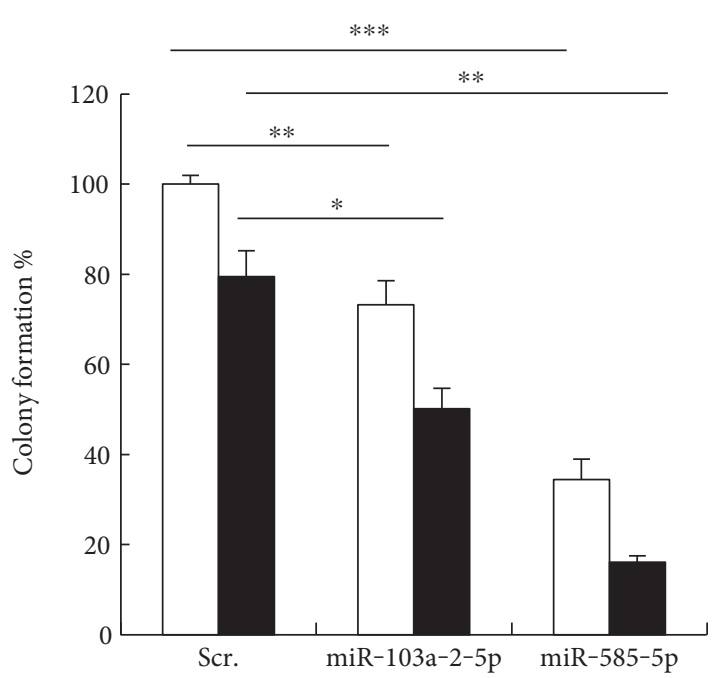

(b)

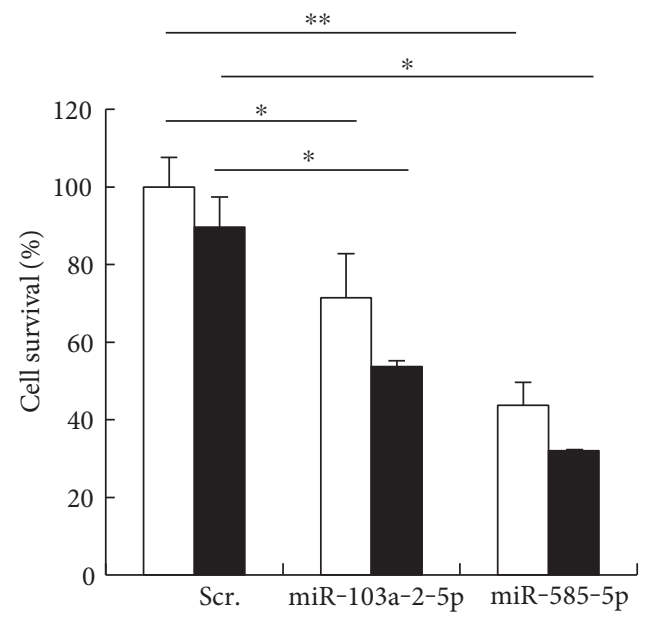

(c)

FIGURE 5: miR-103-2-5p and miR-585-5p decrease colony formation and cell survival. (a, b) HAECs transfected with miR-103a-2-5p, miR-

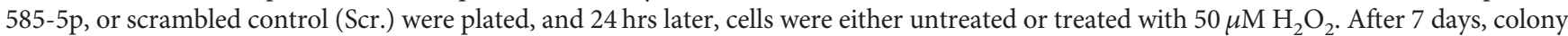
formation was imaged and quantified. (c) HAECs were treated with $100 \mu \mathrm{M} \mathrm{H}_{2} \mathrm{O}_{2}$ for $24 \mathrm{hrs}$, and cell survival was measured by the MTT assay. The histograms are normalized to Scr untreated and represent the mean + SEM from three independent experiments. ${ }^{*} P<0.05$, ${ }^{* *} P<0.01,{ }^{* * *} P<0.001$ by Student's $t$-test.

\section{Discussion}

Previously, we identified miRNAs that were differentially expressed by race and/or hypertension in AA and white women [7]. Our data suggested that differential expression of various miRNA : mRNA pairs may contribute to hypertension etiology. Here, we focused on two miRNAs we identified in our previous studies to better understand mechanistically how they may contribute to hypertension. We found, using bioinformatic analysis based on our gene and miRNA expression levels in hypertensives and subsequent target validation, that miR-103a-2-5p and miR-585$5 p$ both target the DNA damage sensor and repair protein PARP-1. In the context of racial differences in hypertension, we observed higher levels of PARP1 in AAHT compared to AANT. PARP1 levels were also higher in AAHT compared to WHT, but not WHT compared to WNT. These data suggest that differential PARP1 expression is important in hypertension and may have a racial component.

In addition to the miRNAs we found to target $P A R P 1$, other miRNAs have also been shown to target $P A R P 1$, including miR-335, miR-520, miR-489, and miR-223 [41-44]. miR223 is downregulated in the lungs, arteries, and smooth muscle cells of patients with pulmonary hypertension. This decrease in miR-223 expression was regulated by increased activity of hypoxia-inducible factor $1 \alpha$ (HIF $1 \alpha)$, and this in turn upregulated PARP-1 activity and contributed to endothelial dysfunction. Restoration of miR-223 levels decreased PARP-1 activity and restored endothelial function [43]. Therefore, we cannot exclude that these other miRNAs, such as miR-223, may play a role in targeting PARP-1 expression in hypertension. However, we did not observe any significant 
changes in these miRNAs with race or hypertension status in our previous study [7], which indicates that in this context, miR-103a-2-5p and miR-585-5p have roles in systemic arterial hypertension physiology in PARP-1 regulation.

Ample evidence has shown that oxidative stress contributes to hypertension through excessive production of both oxygen and nitrogen-derived free radicals [20, 45]. These species in turn cause DNA damage which can activate PARP-1. PARP-1 plays an important role in repairing damage, generally through poly-ADP-ribosylation of key DNA repair proteins. On the contrary, excessive PARP-1 activation can have detrimental cellular effects through depletion of NAD+ stores and increasing inflammatory pathways [25]. An increase in inflammation can further contribute to hypertension through a myriad of effects including the recruitment and accumulation of inflammatory cells to vessels [20].

As a model system to test the functional interaction of miR-103a-2-5p and miR-585-5p with PARP-1, we overexpressed these miRNAs in primary aortic and umbilical vein endothelial cells. Our overexpression studies, combined with our luciferase reporter assays, indicate that these miRNAs can target PARP1. Furthermore, we found that miR-103a2-5p and miR-585-5p enhanced oxidant-induced DNA damage and cell death. These data are consistent with previous reports that inhibiting PARP-1 enhances DNA damage and decreases cell survival $[37,46]$. In contrast, PARP-1 has also been shown to promote endothelial cell survival in response to oxidative and nitrosative stress [47]. Therefore, PARP-1 plays a complex dual role. The complexity of these roles is illustrated by the fact that mice lacking PARP-1 or overexpressing PARP-1 die prematurely due to age-related pathologies $[25,48]$. In addition, PARP-1 activity and binding to DNA repair proteins are also altered with age [25, 49-51] which may also be relevant considering hypertension increases with age. PARP-1 regulates other cellular processes including transcription, chromatin remodeling, and cell cycle regulation, which may also explain these findings [25]. Nevertheless, these data all point to the important role of PARP-1 in regulating cellular homeostasis.

We used gene expression data from PBMCs to identify and validate miRNA : mRNA regulatory pairs that may play a role in the etiology of hypertension. Previously, we found that miR-585-5p in AAHT was significantly downregulated compared with AANT and WHT [7]. Here, we found that PARP1 expression in PMBCs is increased in AAHT compared with AANT and WHT. Although we validated this functional interaction in endothelial cells, to what degree miR-585-5p regulates PARP1 expression in PBMCs and how that contributes to hypertension etiology remains to be elucidated. miR-103a-2-5p was also predicted to target HIF1A, which regulates the expression of other miRNAs that can regulate PARP1 expression [43]. We observed that HIF1A expression is elevated in AAHT compared with AANT and WHT, and it is possible that miR-103a-2-5p is regulating both PARP1 and indirect upstream regulators, such as HIF1 $\alpha$. The complete pathway of PARP1 regulation will need to be further examined to understand its role in hypertension disparities.

\section{Conclusions}

Here, we have identified that PARP1 is differentially expressed with hypertension and race. Furthermore, we identified that the hypertension-related miRNAs in PBMCs, miR-103a-2-5p and miR-585-5p, target PARP1 in endothelial cells. Our data identifies genomic factors that appear to differentially influence the presence of hypertension among African American and white women. These findings may be useful in developing personalized medicine approaches to the treatment of hypertension in populations at disproportionate risk.

\section{Conflicts of Interest}

The authors declare that they have no conflicts of interest.

\section{Authors' Contributions}

Douglas F. Dluzen and Yoonseo Kim contributed equally to this work.

\section{Acknowledgments}

This research was supported entirely by the Intramural Research Program of the NIH, National Institute on Aging. The authors thank Althaf Lohani and David Freeman for technical assistance and Dr. Ngozi Ejiogu and the HANDLS staff for their careful evaluation and management of study participants.

\section{References}

[1] S. Lewington, R. Clarke, N. Qizilbash, R. Peto, R. Collins, and C. Prospective Studies, "Age-specific relevance of usual blood pressure to vascular mortality: a meta-analysis of individual data for one million adults in 61 prospective studies," Lancet, vol. 360, no. 9349, pp. 1903-1913, 2002.

[2] M. Writing Group, D. Mozaffarian, E. J. Benjamin et al., "Heart disease and stroke Statistics-2016 update: a report from the American Heart Association," Circulation, vol. 133, no. 4, pp. e38-360, 2016.

[3] G. Howard, D. T. Lackland, D. O. Kleindorfer et al., "Racial differences in the impact of elevated systolic blood pressure on stroke risk," JAMA Internal Medicine, vol. 173, no. 1, pp. 46-51, 2013.

[4] L. Te Riet, J. H. van Esch, A. J. Roks, A. H. van den Meiracker, and A. H. Danser, "Hypertension: renin-angiotensinaldosterone system alterations," Circulation Research, vol. 116, no. 6, pp. 960-975, 2015.

[5] A. R. Aroor, V. G. Demarco, G. Jia et al., "The role of tissue renin-angiotensin-aldosterone system in the development of endothelial dysfunction and arterial stiffness," Front Endocrinol (Lausanne), vol. 4, p. 161, 2013.

[6] S. H. Deo, S. W. Holwerda, D. M. Keller, and P. J. Fadel, "Elevated peripheral blood mononuclear cell-derived superoxide production in healthy young black men," American Journal of Physiology. Heart and Circulatory Physiology, vol. 308, no. 5, pp. H548-H552, 2015. 
[7] D. F. Dluzen, N. Noren Hooten, Y. Zhang et al., "Racial differences in microRNA and gene expression in hypertensive women," Scientific Reports, vol. 6, p. 35815, 2016.

[8] H. Guo, N. T. Ingolia, J. S. Weissman, and D. P. Bartel, "Mammalian microRNAs predominantly act to decrease target mRNA levels," Nature, vol. 466, no. 7308, pp. 835-840, 2010.

[9] S. L. Wade, L. F. Langer, J. M. Ward, and T. K. Archer, "MiRNA-mediated regulation of the SWI/SNF chromatin remodeling complex controls pluripotency and endodermal differentiation in human ESCs," Stem Cells, vol. 33, no. 10, pp. 2925-2935, 2015.

[10] R. M. O'Connell, D. S. Rao, A. A. Chaudhuri, and D. Baltimore, "Physiological and pathological roles for microRNAs in the immune system," Nature Reviews. Immunology, vol. 10, no. 2, pp. 111-122, 2010.

[11] E. Hergenreider, S. Heydt, K. Treguer et al., "Atheroprotective communication between endothelial cells and smooth muscle cells through miRNAs," Nature Cell Biology, vol. 14, no. 3, pp. 249-256, 2012.

[12] A. Schober, M. Nazari-Jahantigh, Y. Wei et al., "MicroRNA126-5p promotes endothelial proliferation and limits atherosclerosis by suppressing Dlk1," Nature Medicine, vol. 20, no. 4, pp. 368-376, 2014.

[13] P. Hartmann, Z. Zhou, L. Natarelli et al., "Endothelial dicer promotes atherosclerosis and vascular inflammation by miRNA-103-mediated suppression of KLF4," Nature Communications, vol. 7, p. 10521, 2016.

[14] P. W. Stather, N. Sylvius, J. B. Wild, E. Choke, R. D. Sayers, and M. J. Bown, "Differential microRNA expression profiles in peripheral arterial disease," Circulation. Cardiovascular Genetics, vol. 6, no. 5, pp. 490-497, 2013.

[15] V. Sitras, C. Fenton, and G. Acharya, "Gene expression profile in cardiovascular disease and preeclampsia: a meta-analysis of the transcriptome based on raw data from human studies deposited in gene expression omnibus," Placenta, vol. 36, no. 2, pp. 170-178, 2015.

[16] A. W. Gardner, D. E. Parker, P. S. Montgomery et al., "Gender and racial differences in endothelial oxidative stress and inflammation in patients with symptomatic peripheral artery disease," Journal of Vascular Surgery, vol. 61, no. 5, pp. 1249-1257, 2015.

[17] R. P. Brandes, "Endothelial dysfunction and hypertension," Hypertension, vol. 64, no. 5, pp. 924-928, 2014.

[18] I. Takac, K. Schroder, and R. P. Brandes, "The Nox family of NADPH oxidases: friend or foe of the vascular system?" Current Hypertension Reports, vol. 14, no. 1, pp. 70-78, 2012.

[19] A. Virdis, A. Bacca, R. Colucci et al., "Endothelial dysfunction in small arteries of essential hypertensive patients: role of cyclooxygenase- 2 in oxidative stress generation," Hypertension, vol. 62, no. 2, pp. 337-344, 2013.

[20] R. Loperena and D. G. Harrison, "Oxidative stress and hypertensive diseases," The Medical Clinics of North America, vol. 101, no. 1, pp. 169-193, 2017.

[21] M. De Vos, V. Schreiber, and F. Dantzer, "The diverse roles and clinical relevance of PARPs in DNA damage repair: current state of the art," Biochemical Pharmacology, vol. 84, no. 2, pp. 137-146, 2012.

[22] V. Schreiber, F. Dantzer, J. C. Ame, and G. de Murcia, "Poly(ADP-ribose): novel functions for an old molecule," Nature Reviews. Molecular Cell Biology, vol. 7, no. 7, pp. 517-528, 2006.
[23] B. A. Gibson and W. L. Kraus, "New insights into the molecular and cellular functions of poly(ADP-ribose) and PARPs," Nature Reviews. Molecular Cell Biology, vol. 13, no. 7, pp. 411-424, 2012.

[24] A. Csiszar, P. Pacher, G. Kaley, and Z. Ungvari, "Role of oxidative and nitrosative stress, longevity genes and poly(ADPribose) polymerase in cardiovascular dysfunction associated with aging," Current Vascular Pharmacology, vol. 3, no. 3, pp. 285-291, 2005.

[25] A. Mangerich and A. Burkle, "Pleiotropic cellular functions of PARP1 in longevity and aging: genome maintenance meets inflammation," Oxidative Medicine and Cellular Longevity, vol. 2012, Article ID 321653, p. 19, 2012.

[26] F. Shang, J. Zhang, Z. Li et al., "Cardiovascular protective effect of metformin and telmisartan: reduction of PARP1 activity via the AMPK-PARP1 cascade," PloS One, vol. 11, no. 3, article e0151845, 2016.

[27] G. H. Zhang, M. Chao, L. H. Hui et al., "Poly(ADP-ribose)polymerase 1 inhibition protects against age-dependent endothelial dysfunction," Clinical and Experimental Pharmacology of Physiology, vol. 42, no. 12, pp. 1266-1274, 2015.

[28] G. Kaur, N. Singh, P. Lingeshwar, H. H. Siddiqui, and K. Hanif, "Poly (ADP-ribose) polymerase-1: an emerging target in right ventricle dysfunction associated with pulmonary hypertension," Pulmonary Pharmacology \& Therapeutics, vol. 30, pp. 66-79, 2015.

[29] M. K. Evans, J. M. Lepkowski, N. R. Powe, T. LaVeist, M. F. Kuczmarski, and A. B. Zonderman, "Healthy aging in neighborhoods of diversity across the life span (HANDLS): overcoming barriers to implementing a longitudinal, epidemiologic, urban study of health, race, and socioeconomic status," Ethnicity \& Disease, vol. 20, no. 3, pp. 267-275, 2010.

[30] C. Cheadle, M. P. Vawter, W. J. Freed, and K. G. Becker, "Analysis of microarray data using $\mathrm{Z}$ score transformation," The Journal of Molecular Diagnostics, vol. 5, no. 2, pp. 73-81, 2003.

[31] M. D. Paraskevopoulou, G. Georgakilas, N. Kostoulas et al., "DIANA-microT web server v5.0: service integration into miRNA functional analysis workflows," Nucleic Acids Research, vol. 41, no. Web Server issue, pp. W169-W173, 2013.

[32] K. J. Livak and T. D. Schmittgen, "Analysis of relative gene expression data using real-time quantitative PCR and the 2(-Delta Delta C(T)) method," Methods, vol. 25, no. 4, pp. 402-408, 2001.

[33] N. P. Singh, M. T. McCoy, R. R. Tice, and E. L. Schneider, "A simple technique for quantitation of low levels of DNA damage in individual cells," Experimental Cell Research, vol. 175, no. 1, pp. 184-191, 1988.

[34] A. R. Trzeciak, J. Barnes, N. Ejiogu et al., “Age, sex, and race influence single-strand break repair capacity in a human population," Free Radical Biology \& Medicine, vol. 45, no. 12, pp. 1631-1641, 2008.

[35] T. S. Kumaravel and A. N. Jha, "Reliable comet assay measurements for detecting DNA damage induced by ionising radiation and chemicals," Mutation Research, vol. 605, no. 1-2, pp. 7-16, 2006.

[36] P. L. Olive, J. P. Banath, and R. E. Durand, "Heterogeneity in radiation-induced DNA damage and repair in tumor and normal cells measured using the "comet" assay," Radiation Research, vol. 122, no. 1, pp. 86-94, 1990.

[37] N. Noren Hooten, K. Kompaniez, J. Barnes, A. Lohani, and M. K. Evans, "Poly(ADP-ribose) polymerase 1 (PARP-1) binds to 
8-oxoguanine-DNA glycosylase (OGG1)," The Journal of Biological Chemistry, vol. 286, no. 52, pp. 44679-44690, 2011.

[38] A. Brummer and J. Hausser, "MicroRNA binding sites in the coding region of mRNAs: extending the repertoire of posttranscriptional gene regulation," BioEssays, vol. 36, no. 6, pp. 617-626, 2014.

[39] D. Kim, Y. M. Sung, J. Park et al., "General rules for functional microRNA targeting," Nature Genetics, vol. 48, no. 12, pp. 1517-1526, 2016.

[40] H. Seok, J. Ham, E. S. Jang, and S. W. Chi, "MicroRNA target recognition: insights from transcriptome-wide noncanonical interactions," Molecules and Cells, vol. 39, no. 5, pp. 375-381, 2016.

[41] X. Dong, L. Yang, and H. Wang, "miR-520 promotes DNAdamage-induced trophoblast cell apoptosis by targeting PARP1 in recurrent spontaneous abortion (RSA)," Gynecological Endocrinology, vol. 33, pp. 1-5, 2016.

[42] Y. Luo, L. Tong, H. Meng et al., "MiR-335 regulates the chemo-radioresistance of small cell lung cancer cells by targeting PARP-1," Gene, vol. 600, pp. 9-15, 2017.

[43] J. Meloche, M. Le Guen, F. Potus et al., "miR-223 reverses experimental pulmonary arterial hypertension," American Journal of Physiology. Cell Physiology, vol. 309, no. 6, pp. C363-C372, 2015.

[44] Q. Wei, Y. Liu, P. Liu et al., "MicroRNA-489 induction by hypoxia-inducible factor-1 protects against ischemic kidney injury," Journal of the American Society of Nephrology, vol. 27, no. 9, pp. 2784-2796, 2016.

[45] P. Pacher, A. Vaslin, R. Benko et al., "A new, potent poly(ADPribose) polymerase inhibitor improves cardiac and vascular dysfunction associated with advanced aging," The Journal of Pharmacology and Experimental Therapeutics, vol. 311, no. 2, pp. 485-491, 2004.

[46] M. Rouleau, A. Patel, M. J. Hendzel, S. H. Kaufmann, and G. G. Poirier, "PARP inhibition: PARP1 and beyond," Nature Reviews. Cancer, vol. 10, no. 4, pp. 293-301, 2010.

[47] M. T. Mathews and B. C. Berk, "PARP-1 inhibition prevents oxidative and nitrosative stress-induced endothelial cell death via transactivation of the VEGF receptor 2," Arteriosclerosis, Thrombosis, and Vascular Biology, vol. 28, no. 4, pp. 711717, 2008.

[48] T. S. Piskunova, M. N. Yurova, A. I. Ovsyannikov et al., "Deficiency in poly(ADP-ribose) polymerase-1 (PARP-1) accelerates aging and spontaneous carcinogenesis in mice," Current Gerontology and Geriatrics Research, vol. 2008, Article ID 754190, 11 pages, 2008.

[49] M. Chevanne, C. Calia, M. Zampieri et al., "Oxidative DNA damage repair and parp 1 and parp 2 expression in EpsteinBarr virus-immortalized B lymphocyte cells from young subjects, old subjects, and centenarians," Rejuvenation Research, vol. 10, no. 2, pp. 191-204, 2007.

[50] N. Noren Hooten, M. Fitzpatrick, K. Kompaniez et al., "Coordination of DNA repair by NEIL1 and PARP-1: a possible link to aging," Aging (Albany, NY), vol. 4, no. 10, pp. 674-685, 2012.

[51] M. L. Muiras, M. Muller, F. Schachter, and A. Burkle, "Increased poly(ADP-ribose) polymerase activity in lymphoblastoid cell lines from centenarians," Journal of Molecular Medicine (Berlin, Germany), vol. 76, no. 5, pp. 346-354, 1998. 


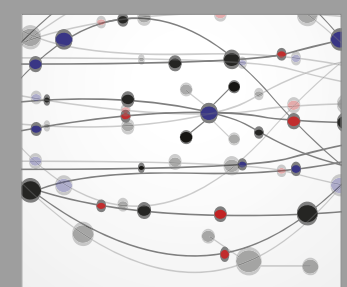

The Scientific World Journal
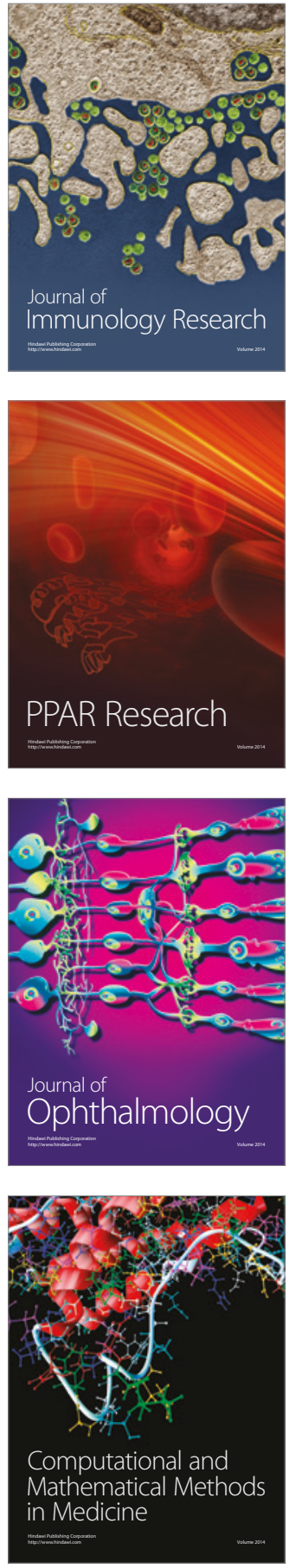

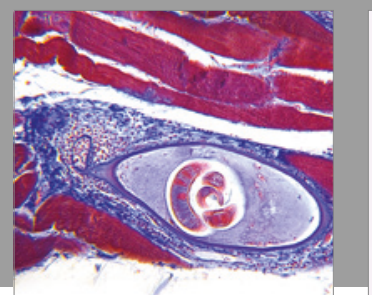

Gastroenterology Research and Practice
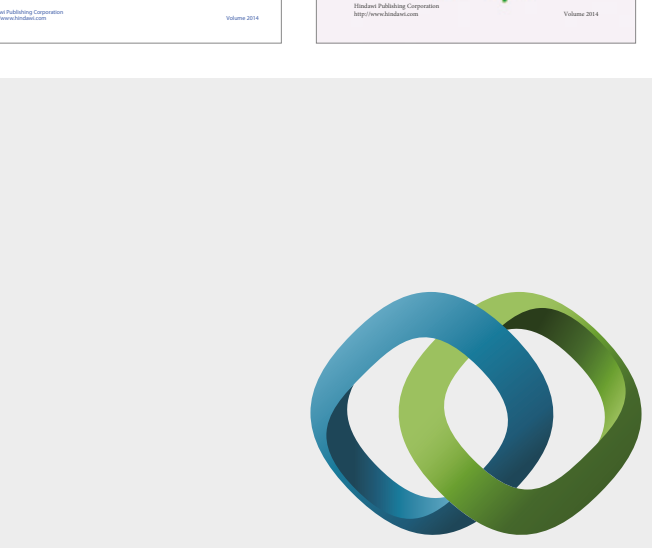

\section{Hindawi}

Submit your manuscripts at

https://www.hindawi.com
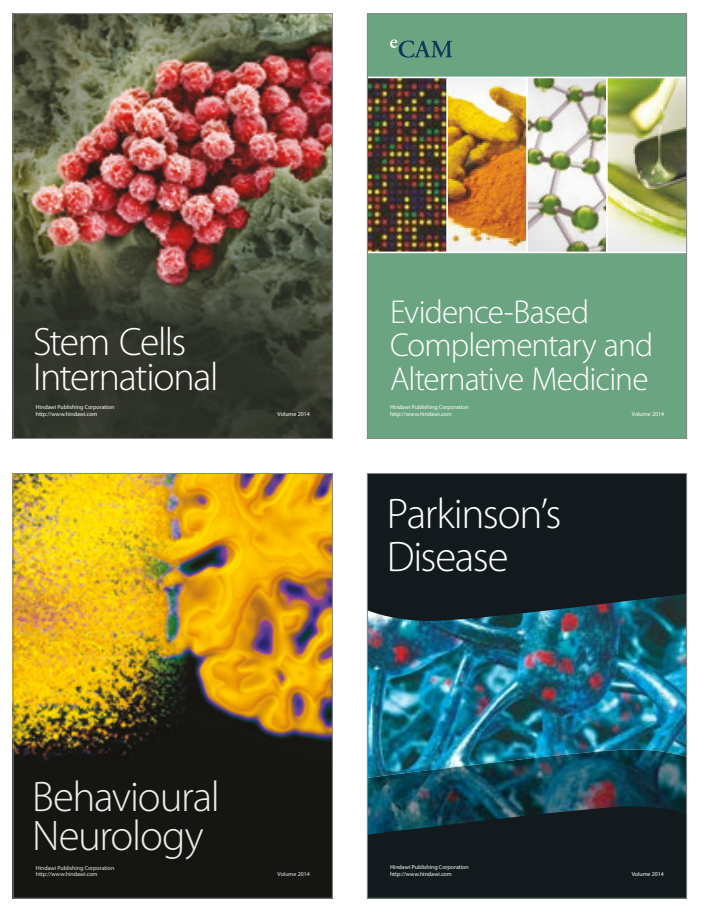
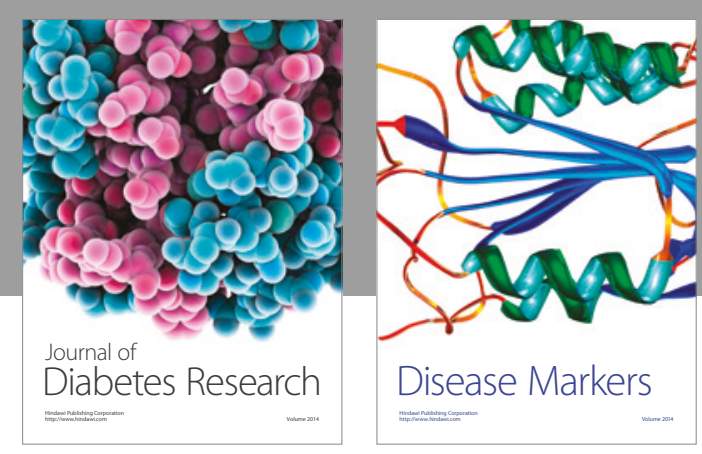

Disease Markers
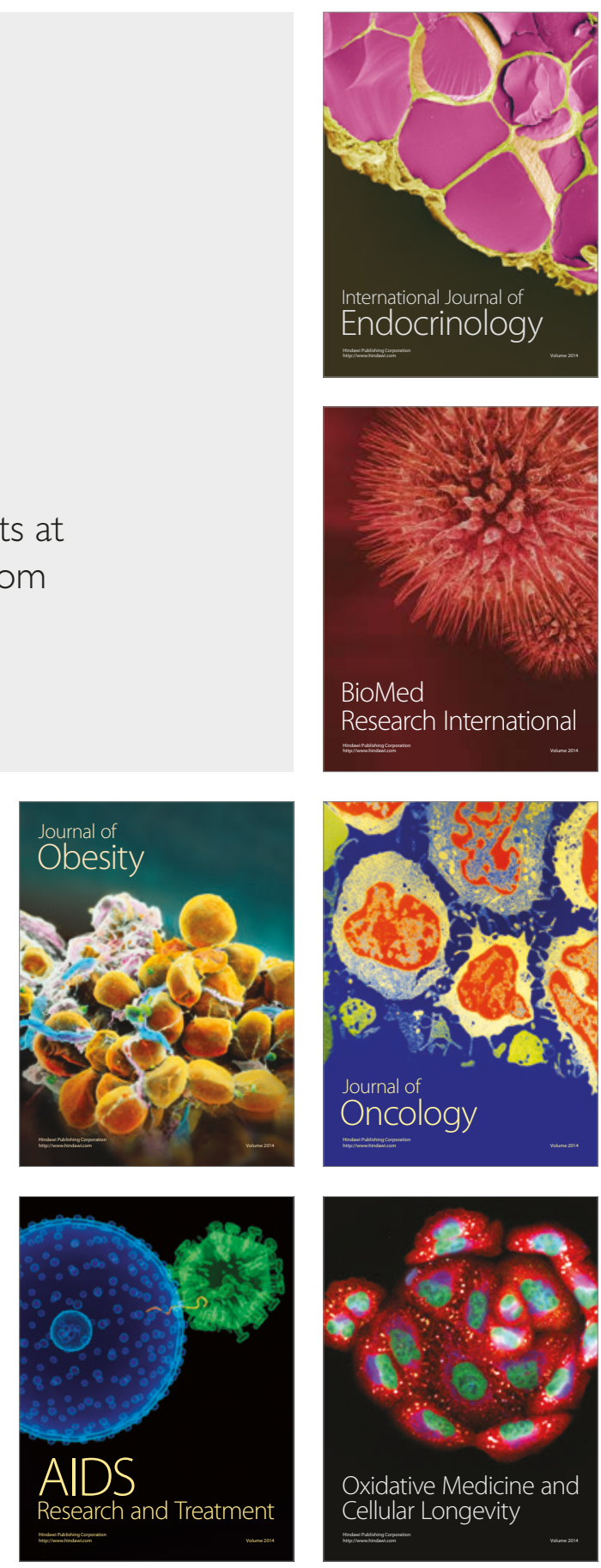